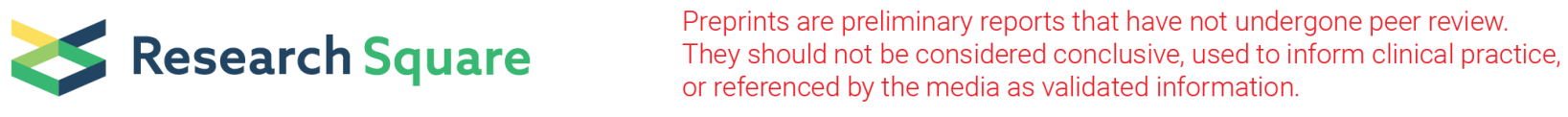

\title{
Prevalence and Allele Frequency of Red-Green Color Vision Defects among School Children in Repi Primary School in Addis Ababa, Ethiopia
}

Wedawek A. Mengesha

Hawassa University

Abebe G. Mengistu

Hawassa University

Zelalem G. Tolesa ( $\square$ basliel2018@gmail.com )

Hawassa University

Research Article

Keywords: Allele frequency, colour blindness, colour vision deficiency, prevalence.

Posted Date: June 18th, 2021

DOI: https://doi.org/10.21203/rs.3.rs-574333/v1

License: (c) (i) This work is licensed under a Creative Commons Attribution 4.0 International License. Read Full License 


\section{Abstract \\ Background}

X-linked red-green color blindness is the most widespread form of vision impairment. The study aimed to determine the prevalence and allele frequencies of red-green color vision impairments among school children in Repi primary school in Addis Ababa, Ethiopia.

\section{Methods}

A cross-sectional survey was employed involving 2400 healthy subjects (females $=850$ and males $=1550$ ) in in Repi primary school. The Ishihara pseudo-isochromatic 24 plate edition was used to test the colour vision of students under natural day light condition.

\section{Results}

The prevalence of congenial colour vision deficiency (CCVD) was 2.29\%; 50 (3.23\%) males and 5 (0.56\%) females were affected with CCVD. The frequencies of achromacy, deutan and protan in male subjects were $0.13 \%, 1.75 \%$, and $0.50 \%$, respectively. Both Deutan and protan were highest among students of Amhara ethnic origin $2.85 \%$ and $1.08 \%$, respectively.

\section{Conclusions}

The overall prevalence of CCVD found in the present study was lower compared to the previous studies done in Ethiopia. There was clear variation in the prevalence of color vision deficiency among students of various ethnic groups. Proper screening, education and counseling are needed to minimize impacts of CCVD in the country, and can also be beneficial for the affected subject in tackling difficulties in everyday work and for proper choice of future profession.

\section{Background}

Three classes of cone photoreceptors lining the retina of the eye, namely, the blue or short wave - sensitive (S), the green or middle - wave sensitive $(\mathrm{M})$, and the red or long $(\mathrm{L})$ wave sensitive determine colour vision in humans $[1,2]$. The three major classes of congenital colour vision deficiency are protan, deutan and tritan types. Recessive mutations and rare genomic rearrangements on the long arm of the $\mathrm{X}$ chromosome encode the gene products that causes protan and deutan defects [3,4]. However, genomic mutations encoding blue retinal cone pigment located on the autosomal chromosome 7 are responsible for tirtan defects $[1,2]$. None congenital colour vision defects could be due to neurological disease, metabolic disorders, drug toxicity, drug overdose etc [2, 5].

The benefits of analyzing the phenotypic and allelic frequencies of congenial colour visions population wise are manifold, for example, occupations/jobs and in routine life that involve prices colour matching to mention few [6]. Managing and organizing data on the prevalence and causes colour vision defects population wise are crucial for vision defect prevention and control; career choice, and prioritization of research activities depending on the severity of problems in the various groups. It is recommended that school children should undergo early diagnosis of colour vision defects to adjust better to tasks at school and to make career choice [2, 5]. To date the number of studies done in Ethiopia, to assess the prevalence of congenital colour vision deficiency are hardly few. Therefore, the objective of the present study was to assess the prevalence congenital colour vision deficiency and allele frequencies among school children at Repi primary school in Addis Ababa, Ethiopia.

\section{Methods}

\section{Study area and study subjects}

Descriptive cross-sectional survey was conducted to determine the prevalence of congenial colour vision deficiency. The study was done at Repi primary school is located in Addis Ababa; focusing on second cycle in grade 7 and 8 students who have normal eye vision condition and who gave their consent were included in the study. A total of 2400 students participated in this study out of which 850(35.42\%) were females and 1550 (64.58\%) were males with an age range from 12 to 16 years with mean age of 15 years. As the sample sizes of the some ethnic groups were small, we had combined them together to have a balanced sample size.

\section{Colour Blindness Test}

The Isihara pseudoisochromatic plates were used to evaluate the colour vision of students under natural day light condition [7]. The number plates of the Ishihara chart were used and the abnormality is differentiated accordingly. The test was done in adequate lighted room resembling natural day light. Testing was carried out by holding the plates $75 \mathrm{~cm}$ away from the student and tilted at right angle to the line of vision. Each student was then 
asked to read the numbers seen in the test plates 1 to 17 in less than 5 seconds and answers were noted down. The normality or defectiveness of color vision and also the type of color blindness were determined by the assessment of the reading of the plates. Thus, an assessment of the reading of plates 1 to 15 determines the normality or defectiveness of color vision. If 13 or more plates are read correctly, the color vision is regarded as normal. If only 9 or fewer plates are read correctly, the color vision was regarded as red-green deficient. Achromacy subjects read correctly plate one only. The plates 16 and 17 are used to differentiate deutan and protan types of colour vision deficiency.

\section{Allele Frequency Analysis}

Assuming that the populations are non-consanguineous, the frequencies of the normal allele $(p)$, deutan allele $(q)$ and protan allele $(r)$ for color blind subjects were calculated based on the Hardy-Weinberg law using the gene counting method as was done by [2]. The expected allele frequencies of females were calculated based on the affected males allele frequencies but the actual allele frequencies of females were calculated based on the affected females as performed by Mitiku et al.[2].

\section{Results}

\section{Phenotypic frequency of congenital colour vision deficiency}

In the present study the prevalence of CCVD in the overall population, male and female subjects were $2.29 \%$ (95\% Cl: 1.8 to 2.78 ), $3.23 \%$ (95\% Cl: 2.8 to 4.00 ) and $0.56 \%(95 \% \mathrm{Cl}: 0.34$ to 0.84 ), respectively (Table 1). Among the male subjects the highest frequency was recorded for Guraghe followed by subjects from Silte ethnic origin (Table 1). Colour blindness was recorded among subjects from 8 ethnic origins, namely; Amhara, Dorze, Gurage, Kembata, Oromo, Silte, Tegaru and Wolaita (Table 1). The frequencies of achromacy, deutan and protan were: $0.13 \%, 1.75 \%$ and $0.50 \%$, respectively (Table 2). The distribution of achromacy, deutan and protan among the male subjects were: $0.19 \%, 2.45 \%$ and $0.77 \%$, respectively (Table 2 ). The distribution of achromacy, deutan and protan among the male subjects were: $0.19 \%, 2.45 \%$ and $0.77 \%$, respectively (Table 2 ).

Table 1

The prevalence of congenital color vision deficiency by gender

\begin{tabular}{|c|c|c|c|c|c|c|c|c|c|}
\hline \multirow[t]{2}{*}{ Ethic groups } & \multicolumn{3}{|l|}{ Male } & \multicolumn{3}{|l|}{ Female } & \multicolumn{3}{|l|}{ Combined } \\
\hline & $\begin{array}{l}\text { Normal } \\
(\%)\end{array}$ & $\begin{array}{l}\text { Affected } \\
\text { (\%) }\end{array}$ & Total & Normal (\%) & Affected (\%) & Total & Normal (\%) & Affected (\%) & Total \\
\hline Amhara & 352(95.91) & $15(4.09)$ & 367 & 94(97.91) & $2(2.08)$ & 96 & 446(96.33) & 17(3.67) & 463 \\
\hline Oromo & 415(97.19) & $12(2.81)$ & 427 & 276(99.28) & $2(0.72)$ & 278 & 691(98.01) & $14(1.99)$ & 705 \\
\hline Dorze & 387(1.77) & $8(2.03)$ & 395 & $95(100.00)$ & $0(0.00)$ & 95 & 482(98.37) & $8(1.63)$ & 490 \\
\hline Guraghe & 74(93.67) & $5(6.33)$ & 79 & $86(100.00)$ & $0(0.00)$ & 86 & $160(96.97)$ & $5(3.03)$ & 165 \\
\hline Silte & 161(95.83) & $7(4.17)$ & 168 & 157(100.00) & $0(0.00)$ & 157 & 318(97.84) & $7(2.15)$ & 325 \\
\hline Other* & 108(97.30) & $3(2.70)$ & 111 & $138(0.99)$ & $1(0.01)$ & 139 & $246(98.4)$ & $4(1.60)$ & 250 \\
\hline Total & 1497(96.77) & $50(3.23)$ & 1547 & $845(99.41)$ & $5(0.56)$ & 850 & 2342(97.71) & $55(2.29)$ & 2397 \\
\hline
\end{tabular}


Table 2

Phenotypic frequency of achromacy and the different types of CCVD among male and female students of various ethnic groups

\begin{tabular}{|c|c|c|c|c|c|c|c|c|c|c|c|c|}
\hline \multirow{2}{*}{$\begin{array}{l}\text { Ethnic } \\
\text { Group }\end{array}$} & \multicolumn{4}{|l|}{ Male } & \multicolumn{4}{|l|}{ Female } & \multicolumn{4}{|l|}{ Combined } \\
\hline & $\begin{array}{l}\text { Achromacy } \\
\text { (\%) }\end{array}$ & $\begin{array}{l}\text { Deutan } \\
(\%)\end{array}$ & $\begin{array}{l}\text { Protan } \\
\text { (\%) }\end{array}$ & Total & $\begin{array}{l}\text { Achromacy } \\
\text { (\%) }\end{array}$ & $\begin{array}{l}\text { Deutan } \\
\text { (\%) }\end{array}$ & $\begin{array}{l}\text { Protan } \\
(\%)\end{array}$ & Total & $\begin{array}{l}\text { Achromacy } \\
\text { (\%) }\end{array}$ & $\begin{array}{l}\text { Deutan } \\
\text { (\%) }\end{array}$ & $\begin{array}{l}\text { Protan } \\
\text { (\%) }\end{array}$ & Total \\
\hline Amhara & $2(0.54)$ & $10(2.71)$ & $5(1.36)$ & 369 & $0(0.00)$ & $2(2.08)$ & $0(0.00)$ & 96 & $2(0.43)$ & $12(2.85)$ & $5(1.08)$ & 465 \\
\hline Oromo & $1(0.23)$ & $9(2.10)$ & $3(0.70)$ & 428 & $0(0.00)$ & $2(0.2)$ & $0(0.00)$ & 278 & $1(0.142)$ & $11(1.56)$ & $3(0.42)$ & 706 \\
\hline Dorze & $0(0.00)$ & $7(1.77)$ & $1(0.25)$ & 395 & $0(0.00)$ & $0(0.00)$ & $\begin{array}{l}0 \\
(0.00)\end{array}$ & 95 & $0(0.00)$ & $7(1.43)$ & $1(0.20)$ & 490 \\
\hline Gurage & $0(0.00)$ & $4(5.06)$ & 1(1.2) & 79 & $0(0.00)$ & $0(0.00)$ & $\begin{array}{l}0 \\
(0.00)\end{array}$ & 86 & $0(0.00)$ & $4(2.42)$ & $1(0.61)$ & 165 \\
\hline Silte & $0(0.00)$ & $6(3.5)$ & $1(0.60)$ & 168 & $0(0.00)$ & $0(0.00)$ & $\begin{array}{l}0 \\
(0.00)\end{array}$ & 157 & $0(0.00)$ & $6(1.85)$ & $1(0.31)$ & 325 \\
\hline Others & $0(0.00)$ & $2(0.00)$ & $1(0.00)$ & 111 & $0(0.00)$ & $1(0.00)$ & $0(0.00)$ & 138 & $0(0.00)$ & $2(0.80)$ & $1(0.40)$ & 249 \\
\hline Total & $3(0.00)$ & $38(0.00)$ & $12(0.00)$ & 1550 & $0(0.00)$ & $5(0.00)$ & $0(0.00)$ & 850 & $3(0.13)$ & $43(1.75)$ & $12(0.50)$ & 2400 \\
\hline
\end{tabular}

\section{Allele Frequency And Heterozygosity}

The frequency of CCVD allele (Table 3) in the present study is lower compared to males in some Indian populations [10] but the frequency is comparable to recent study done in Hawassa, Ethiopia [2]. Similarly, the level of heterozygosity found in the present study among female students of Guraghe, Amhara and Oromo ethnic origin was low compared to that of the population in India [10]. The average heterozygosit for females in the present study was lower compared the prevalence in a general population [17] and a recent study in Hawassa [2]. Furthermore, the frequency of double heterozygote among females in this study is lower relative to that Mitiku et al. [2]. Females who had a recessive allele for deutan on one $\mathrm{X}$ chromosome, but a recessive allele for protan on the second $X$ chromosome are called compound heterozygote [17]. The expected frequency of the compound heterozygote female in the present study is lower compared to the frequency in the general population [17]; and among university students [2]. Similarly, the expected frequency CCVD among the females lower relative to that of the general public (0.39\%)[17].

Table 3 Genotype frequency distribution among male and female

\begin{tabular}{|c|c|c|c|c|c|c|c|c|c|}
\hline \multirow[t]{3}{*}{ ethnic groups } & \multicolumn{9}{|l|}{ Gender } \\
\hline & \multicolumn{4}{|l|}{ Male } & \multicolumn{5}{|l|}{ Female } \\
\hline & Normal & Deutan & Protan & Total & Deutan & Protan & Heterozygote & $\begin{array}{l}\text { Double } \\
\text { heterozygote }\end{array}$ & Color blind \\
\hline \multirow[t]{2}{*}{ Amhara } & 352 & 10 & 5 & 367 & $q^{2}=0.0009$ & $r^{2}=0.0001$ & $2(p q+p r)=0.0768$ & $2 q r=0.001$ & $q^{2}+r^{2}=0.001$ \\
\hline & $p=0.96$ & $q=0.03$ & $r=0.01$ & & & & & & \\
\hline \multirow[t]{2}{*}{ Oromo } & 415 & 9 & 3 & 427 & $q^{2}=0.0004$ & $r^{2}=0.0001$ & $2(p q+p r)=0.0582$ & $2 q r=0.0004$ & $q^{2}+r^{2}=0.001$ \\
\hline & $p=0.97$ & $q=0.02$ & $r=0.01$ & & & & & & \\
\hline \multirow[t]{2}{*}{ Dorze } & 387 & 7 & 1 & 395 & $q^{2}=0.0004$ & $r^{2}=0.000$ & $2(p q+p r)=0.039$ & $2 q r=0.000$ & $q^{2}+r^{2}=0.0004$ \\
\hline & $p=0.98$ & $q=0.02$ & $r=0.00$ & & & & & & \\
\hline \multirow[t]{2}{*}{ Guraghe } & 74 & 4 & 1 & 79 & $q^{2}=0.003$ & $r^{2}=0.0001$ & $2(p q+p r)=0.112$ & $2 q r=0.001$ & $q^{2}+r^{2}=0.003$ \\
\hline & $p=0.94$ & $q=0.05$ & $r=0.01$ & & & & & & \\
\hline \multirow[t]{2}{*}{ Silte } & 161 & 6 & 1 & 168 & $q^{2}=0.0009$ & $r^{2}=0.0001$ & $2(p q+p r)=0.0768$ & $2 q r=0.001$ & $q^{2}+r^{2}=0.001$ \\
\hline & $p=0.96$ & $q=0.03$ & $r=0.01$ & & & & & & \\
\hline Others & 108 & 2 & 1 & 111 & $q^{2}=0.0004$ & $r^{2}=0.0001$ & $2(p q+p r)=0.0582$ & $2 q r=0.0004$ & $q^{2}+r^{2}=0.001$ \\
\hline \multirow[t]{3}{*}{ Total } & $P=0.97$ & $\mathrm{Q}=0.02$ & $R=0.01$ & & & & & & \\
\hline & 1497 & 38 & 12 & 1547 & $q^{2}=0.0004$ & $r^{2}=0.0001$ & $2(p q+p r)=0.0582$ & $2 q r=0.0004$ & $q^{2}+r^{2}=0.001$ \\
\hline & $p=0.97$ & $q=0.02$ & $r=0.01$ & & & & & & \\
\hline
\end{tabular}




\section{Discussion}

\section{Phenotypic frequency of congenital colour vision deficiency}

The overall incidence of CCVD in this study is comparable to the prevalence rates of $2.2 \%$ in Durban, South Africa [8], and slightly higher than $1.5 \%$ the report among school children in Zaria, Northern Nigeria [9]. However, it is lower compared to incidence rates $5.28 \%$ in Manipur, India [10], 3.28\% in Shekhan City/Kurdistan region, Iraq[11] and 2.85\% among university students [2]. The difference in the incidence of CCVD from the current study could be due to difference in study populations, cultural/religious, geographical, ethnicity and techniques of color vision test $[2,5,6,10,12]$.

The prevalence CCVD in male was lower relative to $3.6 \%$ in Wolkite town [13], male school children Pokhara, Western Nepal [14] and Harari (Ethiopia) [12]. Male students of Guraghe ethnic showed the highest prevalence of color blindness followed by Silte, while the students from Dorze ethnic showed least incidence (Table1). The higher incidence in Guraghe and Silte could be due to the practice of some degree of consanguineous marriage in these ethnic groups albeit the degree of such marriage is rare Ethiopia $[2,12]$. The prevalence of color blindness for females is generally low and the finding of this study is no exception. The incidence of CCVD observed in females is lower compared to females in some Indian populations [10] and in Qazvin (Iran)[15] but is larger compared to females in Saudi Arabia [16]. The higher prevalence among males as compared to females shows the genetic causation of the disorder. It is a sex linked recessive trait with defective gene on X-chromosome. Therefore, females may be carriers but are rarely affected because they possess two X-chromosome. On the other hand, males are more prone to develop these disorders as they possess one Xchromosome. Genetically, it reinforces the fact of X-linked recessive nature of the defect $[2,17,18]$.

The frequencies of achromacy, deutan and protan in male subjects were (0.13\%), (1.75\%), and (0.50\%), respectively (Table2). These frequencies are relatively low compared to recent study done by Mitiku et al. [2] among university students at Hawassa, Ethiopia. A comparable frequency of deutan and protan are reported in done in Gish-Abay town by Wale et al. [19]. The slight difference in the prevalence could be due to genetic, geographic, population movements and cultural/religious factors $[2,12,18]$. Deutan cases occur in higher percentage than protan for both male and female subjects. Male subjects from Guraghe ethnic origin had the highest dutan prevalence of followed by Silte, while the subjects from other ethnic combined population showed zero prevalence. The prevalence of deutan in males the present study is lower relative to earlier work done among school children in Abeshge district, Ethiopia [5]. The differences in the frequencies could be attributed to massive population movements and intermixing with other ethnic in metropolitan areas such as Addis Ababa.

The prevalence of CCVD in the present study was lower compared to population in the Middle East, North Africa and Southeast Asia. The lower frequencies of various types of CCVD in the present study compared to populations in the Middle East [20, 21], in North Africa [22,23] and in Southeast Asia $[10,20]$, could be due to the common practices of consanguineous marriage these countries/regions. In Ethiopia consanguineous marriage is rare as it is not promoted because of cultural, religious and legal factors [2, 5, and 12]. Factors like population movements, the molecular structure the gene on the $\mathrm{X}$ chromosome and natural selection could also contribute to the difference in the prevalence of CCVD between population and geographic regions $[2,22,23]$. Population movements between regions and within countries could lead in the rise of the magnitude of exogamous union that that might contribute the increase the incidence of CCVD.

\section{Allele frequency and heterozygosity}

The frequency of CCVD allele (Table3) in the present study is lower compared to males in some Indian populations [10] but the frequency is comparable to recent study done in Hawassa, Ethiopia [2]. Similarly, the level of heterozygosity found in the present study among female students of Guraghe, Amhara and Oromo ethnic origin was low compared to that of the population in India [10]. The average heterozygosit for females in the present study was lower compared the prevalence in a general population [17] and a recent study in Hawassa [2]. Furthermore, the frequency of double heterozygote among females in this study is lower relative to that Mitiku et al. [2]. Females who had a recessive allele for deutan on one $\mathrm{X}$ chromosome, but a recessive allele for protan on the second $X$ chromosome are called compound heterozygote [17]. The expected frequency of the compound heterozygote female in the present study is lower compared to the frequency in the general population [17]; and among university students [2]. Similarly, the expected frequency CCVD among the females lower relative to that of the general public (0.39\%)[17].

\section{Colour Blindness and career choice}

Data on prevalence of CCVD are useful for identifying needs for treatment and rehabilitation services, planning, career choices, and focusing research priorities $[2,5,12,24,25]$. Undiagnosed color vision defect could pose a handicap to the performance of affected students. Color blindness is a nonfatal disorder; therefore colour blind people usually remain unaware of the defect since their vision is otherwise normal [2, 24]. In this study the awareness of school children about colour vision status was low. This intern could affect students in future career choice. Normal color vision is important for our daily life work such as to recognize the traffic signals during crossing roads or to build career in several professions like engineering, soil sciences, chemistry, electricity and electronics, etc [10,24, 25].

\section{Conclusions}

The overall prevalence of congenital colour vision deficiency in the present study was low compared to earlier studies in Ethiopia. School children's awareness about CCVD was very low. Colour vision defects may remain undetected and school children remains unaware about the disability. Such 
undetected defects could cause problems during learning which then resulted into a decline in interest and lesser efficiency in work, preventing the students to reach up to their maximal potential. Therefore, establishing continuous visual screening programs for school children is of paramount importance to minimize the potential impacts of colour vision defects on school children learning capacities. Anomaloscope, the gold standard in color vision test, was not used as it was not available in our set up.

\section{List Of Abbreviations}

CCVD

congenial colour vision deficiency

IRB

Institutional Review Board

\section{Declarations}

\section{Ethics approval and consent to participate}

The study was conducted after ethical approval of the Institutional Review Board (IRB) of Hawassa University (Ethiopia), College of Natural and Computational Sciences; and after informed consent letters were obtained from legal guardians and principal of the school after explanation about the procedures of the test. Currently, the reference number ethical clearance letter is not available but if need be we could request the committee and present the reference number in the future.

\section{Consent for publication}

Consent for publication is not applicable as this study did not include names, images, or videos relating to individual participants.

\section{Availability of data and materials}

The data used in this study are available from the corresponding author on reasonable request.

\section{Competing interests}

We declare that there are no conflicts of interest amongst the co-authors. All the co-authors have contributed from the very inception of the manuscript and until the final version of the manuscript.

\section{Funding}

Research fund was provided by the School of Graduate Studies (SGS) of Hawassa University/Ethiopia. The role of SGS for this research is only to provide research fund for graduate students and researchers. But not involved in the actual research.

\section{Authors' contributions}

WAM was involved in the study design and manuscript writing and revision; AGM was involved in data collection and analyses and ZGT was involved in the study design, data analyses, manuscript writing and revision. All authors read and approved the manuscript.

\section{Acknowledgements}

The authors would like to thank all the participants for their cooperation and Hawassa University for giving ethical permission to conduct the research and for financial support.

\section{Author's details;}

1. Dr. Wendawek A. Mengesha, PhD, Assoc. Prof. Genetics; Department of Biology/HawassaUniversity,email: wendawek0911784046@gmail.com

2. Mr Abebe G. Mengistu, MSc in Biology; Department of Biology/Hawassa University; email: abebegetaneh2121@gmail.com

3. Dr. Zelalem G. Tolesa*, PhD, Asst. Prof. Genetics; Department of Biology/Hawassa University, email: basliel2018@gamial.com

\section{References}

1. Nathans J, Piantanida TP, Eddy RL, Shows TB, Hogness DS. Molecular genetics of inherited variation in human colour vision. Science. 1986; 232(4747):203-10.

2. Mitiku RG, Tolera BS, Tolesa ZG. Prevalence and allele frequency of Congenital Colour Vision Deficiency (CCVD) among students at Hawassa University, Ethiopia. Journal of the Egyptian Public Health Association. 2020 Dec;95(1):1-6. 
3. Jagla WM, Jagle H, Hayashi T, Sharpe LT, Deeb SS. The molecular basis of dichromatic color vision in males with multiple red and green visual pigment genes. Hum Mol Genet. 2002;11(1):23-32.

4. Ueyama H, Muraki-Oda S, Yamade S, Tanabe S, Yamashita T, Shichida Y. Ogita H Unique haplotype in exon 3 of cone opsin mRNA affects splicing of its precursor, leading to congenital color vision defect. Biochem Biophys Res Commun. 2012;424(1):152-7.

5. Mulusew A, Yilikal A. Prevalence of congenital color vision defects among school children in five schools of Abeshge District, Central Ethiopia. The Journal of Ophthalmology of Eastern, Central and Southern Africa. 2013;17(1).

6. Kundu BK, Chakma B. Prevalence of Colour Vision Defect in the Indian Population-Results from a Pre-Employment Screening Centre of a Tertiary Care Hospital. Journal of Contemporary Medical Research. 2020;7(9):I19-23.

7. Ishihara S. The series of plates designed as a test for color deficiency. 24 plates, edition. Tokyo, Japan, KANEHRA SHUPPAN CO., LTD, 1972.

8. Mashige KP, van Staden DB. Prevalence of congenital colour vision deficiency among Black school children in Durban, South Africa. BMC research notes. 2019 Dec;12(1):1-5.

9. Abah ER, Oladigbolu KK, Samaila E, Gani-lkilama A. Ocular disorders in children in Zaria children's school. Nigerian journal of clinical practice. 2011;14(4):473-6.

10. Ahsana SH, Hussain R, Fareed M, Afzal M. Prevalence of red-green color vision defects among Muslim males and females of Manipur, India. Iranian journal of public health. 2013;42(1):16.

11. Abdulrahman MA. Prevalence of Color Vision Deficiency among Students in Hajand and Amad High Schools in Shekhan City. Kurdistan Journal of Applied Research. 2017 Jul 30;2(2):84-8.

12. Geletu, T. T., Muthuswamy, M., and Raga, T. O. (2018). Identification of colorblindness among selected primary school children in Hararghe Region, Eastern Ethiopia. Alexandria journal of medicine, 54(4), 327-330.

13. Woldeamanuel GG. Geta TG Prevalence of colour vision deficiency among school children in Wolkite, Southern Ethiopia. BMC Res Notes. 2018;11:838.

14. Niroula DR, Saha CG. The Incidence of colour blindness among some school children of Pokhara, Western Nepal. Nepal Med Coll J. 2010;12(1):48-50.

15. Khalaj M, Barikani A, Mohammadi M. Prevalence of colour vision deficiency in Qazvin. Zahedan J Res Med Sci (ZJRMS). 2014;16(1):91-3.

16. Alabdelmoneam M. Prevalence of congenital color vision defects in Saudi females of Arab origin. Optometry-Journal of the American Optometric Association. 2011 Sep 1;82(9):543-8.

17. Carroll J. Colour-blindness detective story not so simple. Clinical and Experimental Optometry. 2006 May;89(3):184-5.

18. Fareed M, Anwar MA, Afzal M. Prevalence and gene frequency of color vision impairments among children of six populations from North Indian region. Genes \& Diseases. 2015 Jun 1;2(2):211-8.

19. Wale MZ, Abebe Y, Adamu Y, Zelalem A. Prevalence of color blindness among school children in three primary schools of Gish-Abay town district, Amhara regional state, north-west Ethiopia. BMC ophthalmology. 2018 Dec;18(1):1-6.

20. Karim KJ, Saleem MA. Prevalence of congenital red-green color vision defects among various ethnic groups of students in Erbil City. Jordan Journal of Biological Sciences. 2013 Sep;147(898):1-4.

21. Bener A, Mohammad RR. Global distribution of consanguinity and their impact on complex diseases: Genetic disorders from an endogamous population. Egyptian Journal of Medical Human Genetics. 2017;18(4):315-20.

22. Laghmich A, Alaoui Ismaili FZ, Zian Z, Barakat A, Ghailani Nourouti N, Bennani Mechita M. Hemoglobinopathies in the North of Morocco: Consanguinity Pilot Study. BioMed research international. 2019 Sep 26;2019.

23. Romdhane L, Mezzi N, Hamdi Y, El-Kamah G, Barakat A, Abdelhak S. Consanguinity and inbreeding in health and disease in North African populations. Annual review of genomics and human genetics. 2019 Aug 31;20:155-79.

24. Cole BL. The handicap of abnormal colour vision. Clinical and Experimental Optometry. 2004 Jul;87(4-5):258-75.

25. Abebe Y, Wondmikun Y. Defective color perception among car drivers in Addis Ababa, Ethiopia. Traffic Injury Prevention. 2002 Dec 1;3(4):294-7. 